advise on the records of Grade IV men for the Ministry of National Service. Four members were nominated to serve on a London County Council committee dealing with the lighting of cinemas and eye strain. Committees have been appointed to consider the standardisation of test types and the notation of cylinder axes, and the question of sight-testing by opticians. Two representatives of the Council are serving on the Visual Optics Sub-committee of the Advisory Committee on Technical Optics.

Several subjects of a confidential nature referred to the Council by various public bodies have been dealt with. The expenses of the Council have been defrayed by its members.

\title{
ANNOTATIONS
}

\section{The M.S. in Ophthalmology}

As already noted in these columns $(1919$, p. 430$)$ the University of London has sanctioned the granting of the M.S. degree in two additional branches, one of which is ophthalmology, a fact that can scarcely be too widely known among ophthalmic surgeons. The University's regulations are quoted below in full :

\section{Branch III. Ophthalmology.}

Every candidate for the Degree of Master of Surgery (Branch III) must have taken the Degrees of Bachelor of Medicine and Bachelor of Surgery in this University not less than two years previously, except as provided below.

Candidates who have either

(i) taken the M.B., B.S., Degrees with Honours in Surgery ;

or (ii) subsequently to taking the M.B., B.S. Degrees, conducted a piece of original work approved by the University; *

or (iii) subsequently to taking the M.B., B.S. Degrees had such exceptional experience as may be approved for this purpose by the University, ${ }^{*}$

may present themselves after an interval of one year only from the time of taking the M.B., B.S. Degrees, provided that they comply in other respects with the conditions stated in the following paragraphs.

- Applications under this Section must reach the University not later than three months before the first day of the examination. 
Certificates.-Every candidate must forward together with his form of entry the following certificates: *

1. A certificate of having spent at least two years in the study and practice of Ophthalmology at a teaching school or schools approved by the University, of which one year at least must have been subsequent to obtaining the M.B., B.S. Degrees in this University.

2. A certificate of having held during this time for at least six months an approved appointment + in the Ophthalmic department of a general hospital recognized by the University for the purpose, or at an Ophthalmic hospital recognized by the University.

Details of Examination.-The examination will consist of :

Two papers in Ophthalmology (in one of which there may be included a case for commentary).

One paper in the Principles of Surgery.

A clinical examination.

One paper in the Anatomy and Physiology of the Eye and other parts concerned in Ophthalmology (including Physiological Optics).

One paper in the Pathology of the Eye and other parts concerned in Ophthalmology.

An oral examination.

Candidates shall not be approved by the examiners unless they have shown a competent knowledge in all the subjects of the examination.

\section{Elliot Ophthalmic School}

An event of more than local importance took place recently when Her Excellency Lady Willingdon opened the Elliot Ophthalmic School in connection with the Government Hospital in Madras. This is the outcome of the decision reached by the Government of Madras in 1916 to give theoretical instruction and practical training in ophthalmology side by side in the same building. The Government accordingly sanctioned the construction of a building, at an estimated cost of Rs. 75,750, within the grounds of the Ophthalmic Hospital, and determined to name it after Lieut.-Colonel R. H. Elliot, in recognition of the services rendered by him to ophthalmology in Madras and elsewhere. There is accommodation in the new school for 120 students and graduates, and the tuition will be in the hands of Lieut.-Colonel H. Kirkpatrick and his successors. The section of ophthalmology. in the medical college will be

* (Internal regulations only.) Candidates entering for this examination under Statute 129 will also be required to send in a certificate of having completed the prescribed course of study.

$\dagger \mathrm{A}$ list of these appointments may be obtained on application to the Academic [or External] Registrar. 